\title{
Systemic inflammation, oxidative stress and apolipoprotein B/A1 ratio in active psoriasis: bridging an apparent paradox
}

\author{
Rahul Saxena $^{1}$, Shilpa Suneja ${ }^{2}$, Raj Saxena $^{3}$, Dilutpal Sharma ${ }^{4}$, Alok Milton Lal ${ }^{5}$
}

\author{
${ }^{1}$ Department of Biochemistry, SAHS, Sharda University, Greater Noida, New Delhi, India \\ ${ }^{2}$ Department of Biochemistry, VMMC \& Safdarjung Hospital, New Delhi, India \\ ${ }^{3}$ Department of Clinical Research, Sikkim Manipal University, Manipal, India \\ ${ }^{4}$ Department of Biochemistry, Kings George Medical College, Lucknow, UP, India \\ ${ }^{5}$ Department of Biochemistry \& Biochemical Engineering, JSB \&B, SHIATS, Allahabad, UP, India
}

Received: 15 October 2015

Accepted: 21 November 2015

\author{
*Correspondence: \\ Dr. Rahul Saxena, \\ E-mail: rahulapril@gmail.com
}

Copyright: (c) the author(s), publisher and licensee Medip Academy. This is an open-access article distributed under the terms of the Creative Commons Attribution Non-Commercial License, which permits unrestricted non-commercial use, distribution, and reproduction in any medium, provided the original work is properly cited.

\begin{abstract}
Background: Psoriasis is characterized by systemic increase of inflammation and oxidative stress. In addition, increased incidence of dyslipidemia in dermatological disorders is also in alarming phase. It is conceivable that association of inflammation, oxidative stress and dyslipidemia enhances the future the risk of cardiovascular disease (CVD) in psoriasis patients. The main of the study is to estimate the marker of systemic inflammation, oxidative stress, plasma lipid profile and apolipoprotein levels in psoriasis patients and to determine their role in predicting CVD risk in psoriasis.

Methods: The study population consist of subjects categorized into two groups; Group I: Healthy controls and Group II: Psoriasis patients ( $\mathrm{n}=25$ in each group). Erythrocyte malondialdehyde (MDA), plasma C-reactive protein (CRP) and lipid profile along with apolipoprotein B and A1 were measured and statistically analyzed using standard methods.

Results: Plasma CRP, total cholesterol, triglycerides, LDL-cholesterol and MDA levels were significantly high $(p<0.05)$ in patient group as compared to healthy controls. HDL-cholesterol levels were altered insignificantly $(p<0.1)$ in patient group. Plasma Apo B/Apo A1 ratio were increased significantly $(\mathrm{p}<0.01)$ in patient groups as compared to controls.

Conclusions: Thus, enhanced inflammation, oxidative stress along with increase in Apo B, A1 and its ratio authenticates the fact that these markers are more efficient in prediction of CVD risk in psoriasis patients than conventional lipid profile parameters.
\end{abstract}

Keywords: C- reactive protein, Total cholesterol, Malondialdehyde, HDL-cholesterol, LDL-cholesterol

\section{INTRODUCTION}

It has been well documented that abnormal lipid profile or dyslipidemia in dermatological disorders is an alarming condition of future health complications predominantly cardiovascular diseases (CVD) such as myocardial infarction, atherosclerosis etc. ${ }^{1}$ Amusingly, the concentrations of apolipoprotein B (ApoB) and apolipoprotein A1 (Apo A1) as well as the ratio of Apo-B I Apo A1 have received much attention in prediction of CVD risk. ${ }^{2}$ 
Psoriasis is one of the chronic and recurrent inflammatory skin disorders that have been associated with oxidative stress, abnormal plasma lipid metabolism. ${ }^{3}$ The clinically active psoriasis lesions reveal infiltration of $\mathrm{WBC}$, and several studies report high levels of WBC activation products in the peripheral blood of these patients. ${ }^{4,5}$ It has been suggested that C-reactive protein, an acute phase reactants, synthesized in liver and raised by many folds following acute inflammation, is a marker of systemic inflammation in several conditions including psoriasis, rheumatoid arthritis, tuberculosis, cancer, and myocardial infarction. ${ }^{6}$

Oxidative stress ensues when large amount of reactive oxygen species are produced in the cells, that can evade or overwhelm the antioxidant protective mechanisms of cells and tissues, and produce major interrelated impaired cell metabolism including DNA strand breakage, rises in intracellular free $\mathrm{Ca}_{2}^{+}$, damage to membrane ion transporters and other specific proteins leading to cell death. Prime target to free radicals attack are the polyunsaturated fatty acids in the membrane lipids, causing lipid peroxidation, has been found to be a major event in the development of various diseases. ${ }^{7,8}$ Lipid peroxide (malonaldialdehyde) is the most abundant among the reactive aldehydes derived from lipid peroxidation. It has been suggested that binding to these aldehydes to membrane protein may alter their function, tonicity, permeability, rigidity and integrity, and thereby may induce culprit effect. ${ }^{9}$ In addition, presence of inflammation further enhances the frequency to develop CVD. ${ }^{10}$

It is conceivable that there is a close link between systemic inflammation, oxidative stress and dyslipidemia in increasing the frequency of CVD risk in psoriasis patients. Inspite of improvement in our knowledge on psoriasis from pathologic point of view, the intimate mechanisms involving systemic inflammation, oxidative stress and dyslipidemia in psoriasis patients making them more susceptible to develop future CVD are complex and not yet fully understood. In addition, as best of our knowledge, previous studies on psoriasis patients have not included systemic inflammation, oxidative stress and dyslipidemia in a single setting. ${ }^{11-13}$ Therefore, the present work aims to evaluate the levels of c-reactive protein (CRP), MDA, lipid profile and Apo B/A1 ratio in active psoriasis patients and to determine their role in prediction of CVD risk in same population.

\section{METHODS}

In the present study, 32 psoriasis patients were screened for active psoriasis (having more than $10 \%$ body area covered with severe psoriasis lesion) and 25 patients with active psoriasis (18 males and 7 females of 30-50 years age group) were recruited (Group II). Age and sex matched 25 normal healthy volunteers do not have skin disorder were recruited as controls (Group I).
These subjects were recruited only after taking their informed consent and approval of protocol by ethics committee of college. A general information or preexperimental questionnaire regarding demographic information, family history and limited physical examination including involvement of the body area according to the rule of nine, was completed from all the subjects.

\section{Inclusion criteria}

Subjects, who gave informed consent for study, having no history of cardio vascular disease, don't under any medical treatment (local steroid medication, any phototherapy treatment) or taking antioxidant supplement for at least 1 month prior to blood collection were included.

\section{Exclusion criteria}

Patients with diabetes mellitus, arthritis, hypertension, renal insufficiency, hepatic disease, acute illness such as fever, joint pain, abdominal complaint, malignancy, history of chest pain, deep fungal or disseminated localized gonococcal infection, or under any medicinal were excluded.

Blood samples (approximately $10 \mathrm{ml}$ ) were collected in sterile EDTA vials by venous puncture from overnight fasting subjects. Plasma was separated by centrifugation of blood at $1000 \mathrm{~g}$ for $15 \mathrm{~min}$ at room temperature and stored at $-80^{\circ} \mathrm{C}$ until use. Plasma CRP levels were measured using commercially available ELISA kits (R\&D Systems, USA), according to manufacturer's instructions. Plasma lipid profile contents (Total Cholesterol, Triglycerides and HDL cholesterol) were analysed enzymatically using kit obtained from (Randox Laboratories Limited, Crumlin, UK). LDL-cholesterol levels were calculated by Friedwald's formula. ${ }^{14}$

$$
L D L-\mathrm{C}=T C-\left[\frac{T G}{5}+\mathrm{HDL}-\mathrm{C}\right]
$$

Plasma apolipoproteins B, A1 were done using immunoturbidity method (Randox kit) and ApoB/A1 ratio was calculated. Erythrocyte malondialdehyde (MDA) levels were measured as thiobarbituric acid reactive substances, after preparation of hemolysate. The heat induced reaction of MDA with thiobarbituric acid (TBA) in the acid solution formed a trimethine coloured substance, which was measured spectrophotometrically at $532 \mathrm{~nm}^{15}$

\section{Statistical analysis}

The data collected from study group subjects were entered separately in Microsoft Excel sheet of windows 2007 and values were expressed as Mean \pm SD. The significance of mean difference between study group subjects was compared by using Student's t test. The 
distribution of ' $t$ '- probability was calculated depending on ' $n$ ' and significance of test was obtained. $P$ value $<0.05$ and $<0.001$ were considered as significant and highly significant respectively.

\section{RESULTS}

The demographic indices including mean age and blood pressure of the study group subjects, as observed in present study, are depicted in Table 1. Patients with psoriasis have insignificant variation $(\mathrm{p}<0.1)$ with respect to age and blood pressure, as compared to healthy controls. Marker of systemic inflammation and oxidative stress status are presented in Table 2. Plasma CRP and erythrocyte MDA levels were found to be significantly high ( $\mathrm{P}<0.001 ; 40.06 \%$ and $\mathrm{p}<0.05 ; 28.6 \%$ high $)$ in patient group as compared to healthy controls which reflect the role of inflammation and oxidative stress in disease process. Plasma lipid profile along with apolipoproteins levels, as depicted in Table 2 revealed that Plasma total cholesterol, triglycerides and LDL cholesterol levels were significantly high ( $\mathrm{p}<0.05,32.5 \%$, $26.4 \%$ and $30.1 \%$ high) in patient group as compared to healthy controls. However, HDL cholesterol levels were altered insignificantly ( $\mathrm{p}<0.1,17 \%$ low) in patient group. In addition, plasma ApoB/Apo A1 ratio were increased significantly $(\mathrm{p}<0.01)$ in patient groups as compared to controls.

Table 1: Demographic and clinical profile of study group subjects (Mean \pm SD).

\begin{tabular}{|lll|}
\hline Particulars & $\begin{array}{l}\text { Group I } \\
(\mathbf{n = 2 5})\end{array}$ & $\begin{array}{l}\text { Group II } \\
(\mathbf{n = 2 5})\end{array}$ \\
\hline Age (years) & $38 \pm 5$ & $42 \pm 5.4$ \\
\hline Male/Female & $15 / 10$ & $18 / 07$ \\
\hline Height (meter) & $1.59 \pm 0.30$ & $1.60 \pm 0.28$ \\
\hline Weight $(\mathrm{Kg})$ & $61.2 \pm 2.4$ & $58.5 \pm 1.8$ \\
\hline BMI $\left(\mathrm{Kg} / \mathrm{m}^{2}\right)$ & $24.4 \pm 1.3$ & $22.8 \pm 1.2^{*}$ \\
\hline $\begin{array}{l}\text { Systolic blood } \\
\text { pressure }(\mathrm{mmHg})\end{array}$ & $108.5 \pm 3.2$ & $112.0 \pm 3.8^{*}$ \\
\hline $\begin{array}{l}\text { Diastolic blood } \\
\text { pressure(mmHg) }\end{array}$ & $76.4 \pm 2.30$ & $77.2 \pm 2.45^{*}$ \\
\hline
\end{tabular}

${ }^{*} \mathrm{p}<0.1$ : Non-significant; ${ }^{* *} \mathrm{p}<0.05$ : Significant

Table 2: Marker of systemic inflammation, oxidative stress and plasma lipid profile in study group subjects (Mean \pm SD).

\begin{tabular}{|lllll|}
\hline Particulars & Group I $(\mathbf{n = 2 5})$ & Group II $(\mathbf{n = 2 5})$ & $\%$ increase & \% decrease \\
\hline CRP $(\mathrm{mg} / \mathrm{L})$ & $3.32 \pm 0.15$ & $4.65 \pm 0.15^{* * * * *}$ & $40.06 \%$ & - \\
\hline Malondialdehyde $(\mu \mathrm{molMDA} / \mathrm{ml})$ & $2.70 \pm 0.15$ & $3.47 \pm 0.23^{* * *}$ & $28.6 \%$ & - \\
\hline Total Cholesterol $(\mathrm{mg} / \mathrm{dl})$ & $156.65 \pm 14.6$ & $207.56 \pm 19.2^{* * *}$ & $32.5 \%$, & - \\
\hline Triglycerides $(\mathrm{mg} / \mathrm{dl})$ & $105.82 \pm 12.30$ & $133.7 \pm 18.4^{* *}$ & $26.4 \%$ & - \\
\hline HDL cholesterol $(\mathrm{mg} / \mathrm{dl})$ & $45.6 \pm 3.48$ & $37.85 \pm 3.21^{* *}$ & - & $17.0 \%$ \\
\hline LDL cholesterol $(\mathrm{mg} / \mathrm{dl})$ & $94.7 \pm 12.54$ & $123.20 \pm 13.5^{* *}$ & $30.1 \%$ & - \\
\hline Apo-B $(\mathrm{mg} / \mathrm{dl})$ & $92.54 \pm 18.0$ & $113.5 \pm 26.8^{* * *}$ & $22.54 \%$ & - \\
\hline Apo-A(mg/dl) & $142.34 \pm 28.6$ & $97.84 \pm 19.14^{* * *}$ & - & $31.26 \%$ \\
\hline Apo-B/A1 & $0.68 \pm 0.17$ & $1.24 \pm 0.45^{* * * *}$ & $82.35 \%$ & - \\
\hline
\end{tabular}

${ }^{*} \mathrm{p}<0.1$ : Non-significant; $* * \mathrm{p}<0.05$ : Significant; $* * \mathrm{p}<0.001$ : Highly significant

\section{DISCUSSION}

Many dermatological disorders are known to be associated with dyslipidemia. Psoriasis is one of the chronic inflammatory, immune mediated skin disorders affecting $2-3 \%$ of the population. ${ }^{16}$ It is speculated that occurrence of inflammation in psoriasis is associated with dyslipidemia and oxidative stress with unsolved conundrum and the mechanism behind its complex interplay is responsible for the development of future CVD risk. In the present study plasma CRP levels were found to be significantly high in psoriasis patient along perturb lipid profile and increased apolipoprotein B/A1 ratio as compared to healthy controls. Our findings are in concordance with that of several previous studies conducted separately and involving relatively small patient populations. ${ }^{6,11,13}$ According to them enhanced inflammation induces the development of atherogenic dyslipidemic profile in psoriasis patients by modulating the lipoprotein lipase activity via antilipoprotein lipase antibodies. In addition, atherogenic complexes of autoantibodies to oxidized LDL are generated in response to an oxidative inflammatory effect which enhances the accumulation of LDL in the endothelial wall and thereby enhances the CVD risk in psoriasis patients. ${ }^{17}$

Perturbation of systemic oxidative balance, i.e. uncontrolled ROS production plays a crucial role in enhancing the disease complexity in psoriasis. $^{12}$ Endothelial cells and vascular smooth cells produce ROS which oxidize low density lipoprotein and thereby initiate atherosclerosis. In addition, involvement of ROS in cell membrane damage via lipid peroxidation and its resultant products such as lipid radicals $\left(\mathrm{L}^{\circ}\right)$, lipid peroxides $\left(\mathrm{LOO}^{\circ}\right)$, lipid hydroperoxides and highly reactive aldehydes which play a crucial role in the development and progression of vascular complications in psoriasis. ${ }^{18}$ In this context, marked increase in erythrocyte MDA 
levels (i.e. marker of lipid peroxidation) were observed in group II subjects $(\mathrm{p}<0.005)$ as compared to healthy controls which clarify the etio-pathogenic role of ROS via lipid peroxidation, in shaping psoriasis patients more susceptible to develop future incidence of CVD and its related complications. Our findings were in concordance with that of previous study carried out on psoriasis patients having CVD risk. ${ }^{1,3}$ According to them, lipid peroxides are toxic to the cellular components, and responsible for not only initiation of complex cascade that promotes atherosclerotic plaque formation, prostacyclin synthesis, enhancement of cytosolic free calcium and peripheral vascular resistance and thereby leading to development of CVD complications in psoriasis patients with abnormal lipid profile. ${ }^{12,19}$

\section{CONCLUSION}

On the basis of present findings, it can be inferred that apart from lipid profile, regular assessment of apolipoproteins along with markers of inflammation and oxidative stress should be included to predict CVD complication. Moreover, dietary counseling may help in the control of the primary disorder and enable them to reduce the cardiovascular risks. Furthermore, life style modification, regular exercise and antioxidant rich diet should be incorporated along with prescribed drug for psoriasis treatment so that two important goal of CVD prevention i.e. maintenance of healthy lipid profile and regulation of inflammation along with oxidative stress can be easily achieved.

\section{ACKNOWLEDGEMENTS}

Authors are thankful to entire department of Dermatology for active participation and co-operation in the study. All the authors have equally contributed.

\section{Funding: No funding sources}

Conflict of interest: None declared

Ethical approval: The study was approved by the Institutional Ethics Committee

\section{REFERENCES}

1. Neimann AL, Shin DB, Wang X, Margolis DJ, Troxel $\mathrm{AB}$, Gelfand JM. Prevalence of cardiovascular risk factors in patients with psoriasis. J Am Acad Dermatol. 2006;55:829-35.

2. Walldius G, Jungner I, Holme I, Aastveit AH, Kolar W and Steiner E. High apolipoprotein B, low apolipoprotein A-I, and improvement in the prediction of fatal myocardial infarction (AMORIS study): a prospective study. Lancet .2001;358: 2026-33.

3. Rocha-Pereiraa P, Santos-Silvac A, Rebeloc I, Figueiredoe A, Quintanilha A, Teixeira F. Dislipidemia and oxidative stress in mild and in severe psoriasis as a risk for cardiovascular disease. Clinica Chimica Acta. 2001;303:33-9.

4. Orem A, Deger O, Cimsit G, Bahadir S. Plasma polymorphonuclear leukocyte elastase levels and its relation to disease activity in psoriasis. Clin Chim Acta. 1997;264:49-54.

5. Rocha-Pereira P, Rebelo I, Santos-Silva A, Figueiredo A, Ferra MIA, Quintanilha A et al. Leukocyte activation and oxidative stress in psoriasis. $\mathrm{Br} \mathrm{J}$ Pharmacol. 1999;127:83.

6. Paller D, Petrou I. Pediatric psoriasis: C-reactive protein levels associated with disease severity. J Invest Dermatol. 2009;102:219-27.

7. Bhattacharya I, Saxena R, Gupta V. Efficacy of vitamin $\mathrm{E}$ in knee osteoarthritis management of North Indian Geriatric population. Therap Adv Musculo Dis. 2012;4(1):11-9.

8. Singh S, Saxena R, Lal AM. Influence of aging on plasma ascorbate level. Natl Acad Sci Lett. 2005;28(3\&4):125-7.

9. Shoe M, Jackson C and Yu BP. Lipid peroxidation contributes to age related membrane rigidity. Free Rad Bio Med. 1995;18:977-84.

10. Saxena R, Bhattacharya I, Saxena, R. Susceptibility of Knee Osteoarthritic patients to develop Cardiovascular disease. Asian J Medical Sciences. 2013;4(3):62-8.

11. Isha, Jain VK, Lal H. C-Reactive Protein and Uric Acid Levels in Patients with Psoriasis. Ind $\mathrm{J}$ Clin Biochem. 2011;26(3):309-11.

12. Kökçam I, Naziroğlu M. Antioxidants and lipid peroxidation status in the blood of patients with psoriasis. Clin Chim Acta. 1999;289(1-2):23-3.

13. Toker A, Kadi M, Yildirim AK, Aksoy H, Akçay F. Serum lipid profile paraoxonase and arylesterase activities in psoriasis. Cell Biochem Funct. 2009;27(3):176-80.

14. Friedewald WT, Levy RI and Fredrickson DS. Estimation of the concentration of low-density lipoprotein cholesterol in plasma, without use of the preparative ultracentrifuge. Clin Chem. 1972,18:499502.

15. Sinnhuber RO, Yu TC, Yu TC. Characterization of the red pigment formed in the thiobarbituric acid determination of oxidative rancidity. Food Res. 1958;23:626-30.

16. Gisondi P, Ferrazzi A, Girolomoni G. Metabolic comorbidities and psoriasis. Acta Dermatovenerol Croat. 2010;18:297-304.

17. Hahn BH, Grossman J, Chen W, Mc Mahon M. The pathogenesis of atherosclerosis in autoimmune rheumatic diseases: Roles of inflammation and dyslipidemia. J Autoimmun. 2007;28:69-75.

18. Saxena R, Mehrotra V. Prediction of hypertension and cardiovascular disease risk in North Indian geriatric population: a conundrum of senescence. Int J Comm Med Public Health. 2014;1(1):18-23.

19. Dutta J, Sharma D, Saxena R. Oxidative stress mediated electrolyte imbalance in 30 known cases of knee osteoarthritis patients: A clinical approach. Asian J Medical Sciences. 2015;6(5):26-30.

Cite this article as: Saxena R, Suneja S, Saxena R, Sharma D, Lal AM. Systemic inflammation, oxidative stress and apolipoprotein B/A1 ratio in active psoriasis: bridging an apparent paradox. Int J Res Dermatol 2015;1:10-3. 